\title{
Industrial dynamics and economic growth in health-care context. Evidence from selected OECD countries
}

\author{
Song Ying \\ Research Center for Economy of Upper Reaches of the Yangtze River, School of Economics, \\ Chongqing Technology and Business University, Chongqing, China and School of Business Administration, \\ Dongbei University of Finance and Economics, Dalian, China \\ Daniele Leone \\ Department of Management Studies and Quantitative Methods, University of Naples Parthenope, Napoli, Italy \\ Antonella Francesca Cicchiello \\ Department of Economics and Law, Catholic University of Sacred Heart, Piacenza, Italy, and \\ Amirreza Kazemikhasragh \\ University Program of Studies on Asia and Africa (PUEAA), National Autonomous University of Mexico (UNAM), Mexico City, Mexico
}

\begin{abstract}
Purpose - The economic shock posed by the current COVID-19 outbreak brought out a worldwide public health emergency with a close relationship between the industrial marketing practices, the health level of society and its economic development. The purpose of this study is to analyse the industrial dynamics in health care and their impact on economic growth and health status.

Design/methodology/approach - To empirically investigate the relationship between growth and health, the authors use a data set drawn from 29 selected Organisation for Economic Co-operation and Development (OECD) countries over the period 2000 and 2019. Using panel regressions, the authors investigate the impact of the health-care industry measured in terms of health status, health expenditure, sales on pharmaceutical products, the number of persons working in health care and the coverage by private health insurances. Fixed effect and random effect regressions are used to estimate this model.

Findings - Overall, the results are suggestive of a nexus between the industrial marketing dynamics of health-care context and economic growth both interacting and improving each other. As the quality of the health-care market enhances, the economy grows richer and the health status of the population improves considerably.

Practical implications - To support health-care markets in OECD countries, health policymakers need to formulate a long-term industrial health policy that addresses all the social and individual determinants of health.

Originality/value - To the best of the knowledge, this is the first study to provide a better understanding of the relationship between health-care industrial dynamics and economic growth in OECD countries along different dimensions.
\end{abstract}

Keywords Industrial markets, Industrial marketing strategies, Health-care industry, Economic growth, OECD countries

Paper type Research paper

\section{Introduction}

The industrial dynamics in health-care context has received increasing attention as a determinant of economic growth, both in developed and developing countries (Bloom et al., 2004, 2019; Piabuo and Tieguhong, 2017; Well, 2007). Increasing health care expenditures for industrial performance prolongs life expectancy and increases general safety and welfare (Bedir, 2016). A strong consensus has emerged in the past decade that the health-care organisations have to redesign their industrial marketing strategies to search for a competitive advantage in

The current issue and full text archive of this journal is available on Emerald Insight at: https://www.emerald.com/insight/0885-8624.htm

Journal of Business \& Industrial Marketing 37/8 (2022) 1706-1716

Emerald Publishing Limited [ISSN 0885-8624] [DOI 10.1108/JBIM-11-2020-0513] this complex context (Hwang and Christensen, 2008; Schiavone and Simoni, 2019; Crick and Crick, 2020). Recent scholars have recognised that health-care industrial performance and economic growth are connected (Lee et al., 2011; Jamaludin et al., 2013). Refining the management of resources through strategic marketing approaches in the healthcare industry is essential for economic growth and political

(C) Song Ying, Daniele Leone, Antonella Francesca Cicchiello and Amirreza Kazemikhasragh. Published by Emerald Publishing Limited. This article is published under the Creative Commons Attribution (CC BY 4.0) licence. Anyone may reproduce, distribute, translate and create derivative works of this article (for both commercial and non-commercial purposes), subject to full attribution to the original publication and authors. The full terms of this licence may be seen at http:// creativecommons.org/licences/by/4.0/legalcode

Received 18 November 2020

Revised 2 June 2021

22 July 2021

Accepted 26 July 2021 
stability (Wright and Taylor, 2005; Anderson et al., 2019; Yildirim and Calıskan, 2020; Crick and Crick, 2020).

The economic shock posed by the current COVID-19 outbreak, which continues to spread internationally causing a worldwide public health emergency is a demonstration of the close relationship between the health-care industrial performance, the health level of society and its economic development. As the dire consequences caused by the COVID-19 pandemic become more and more evident, issues of population health become even more relevant than they were before. Improving the health status of a population means to improve the physical and mental health outcomes and well-being of people by making health care services more widely available to all, whilst reducing health inequalities. It requires action to deliver appropriate health and care services and reduce the occurrence of ill health.

Sustained health expenditure, for example, improves the health status of workers by causing increased labour efficiency and productivity and, consequently, higher economic growth (Schultz, 2005). Generally, healthier people can work harder and longer. At the same time, given the existence of bidirectional causality running between health expenditure and income (Erdil and Yetkiner, 2004), increases in health expenditures for industrial performance make possible higher labour supply and productivity, which lead to a higher income. The effects of the industry on the economy are significant not only because industrial dynamics affect people's health and their productivity but also because today health represents one of the largest economic industries in all middle and high-income countries.

In this study, we explore the industrial dynamics in health-care context and their impact on economic growth and health status in 29 selected Organisation for Economic Co-operation and Development (OECD) countries. We assume that quality health industrial practices contribute to improving the health and wellbeing of the population, which are of vital interest to everyone, their families and communities and are essential for the economic and social development of countries. The entire health-care ecosystem and its importance continue to grow and, with it, the relevance of its contribution to the achievement of broader objectives about managing the access, value and sustainability of care. Indeed, health-care ecosystem is formed by the organised set of people, institutions and resources that hold public responsibility for the industry practices in providing health-care to all citizens without distinction of gender, age, income and work (Frow et al., 2016). In addition, a market access approach for establishing supply conditions that reduce the time to market for drugs or medical devices in health care has been the object of study from different industrial perspectives (Schiavone and Simoni, 2019; Huang et al., 2020). For these reasons, we advance our study as an important innovation and research engine for industrial marketing literature and a stimulus for competition between professionals, innovative practices and products.

This background forms the basis of our motivation to explore the topic of this paper with the following research question:

RQ1. How does the effectiveness and efficiency of the healthcare industrial dynamics contribute to improving health status and economic growth?

To empirically investigate the relationship between growth and health, we use a data set drawn from 29 selected OECD countries over the period 2000 and 2019. As discussed in detail below, our work finds that as the health-care industrial performance advances the economy grows richer and health status improves considerably. In line with previous studies (Gupta and Mitra, 2004), the interdependence of economic growth and health is empirically verified. Indeed, better performance of the economy produces more resources to spend on health-care industrial marketing practices and better health status improves productivity, and therefore, economic growth. Results also show that per capita health industrial expenditure improves health status and also appears to raise growth. In addition, more performing sales channels in the commercial sector of the pharmaceutical market, as well as an increase in the health-care workforce and in private health insurance (PHI) coverage led to higher health status and economic growth.

Industrialisation, infrastructure and urbanisation have positive impacts on economic growth. The health status is seen to vary positively with urbanisation and infrastructure and inversely with industrialisation. Whilst there is a growing body of research analysing the relationship between health and economic growth (Piabuo and Tieguhong, 2017; Bloom et al., 2019), to the best of our knowledge, this is the first study to provide a better understanding of the relationship between health-care industrial dynamics and economic growth in OECD countries along different dimensions, namely, health status, health expenditure, sales on pharmaceutical products, the number of persons working in health care and the coverage by PHIs.

Finally, with the exploratory study, we contribute to existent management studies by providing implications for practitioners, scholars and institutions who intend to take advantage of the opportunities offered by the health-care industry. The remainder of this article is structured as follows. Section 2 reviews the main theoretical contributions. Section 3 provides data and econometric approach used in the study. Empirical findings are discussed in Section 4. The main conclusions and implications are stated in Sections 5-7.

\section{Theoretical background}

2.1 The dynamics of industrial marketing in health care Health care is an ever-changing industry where companies are constantly faced with the marketing challenges and opportunities arising from a rapidly changing operating environment and evergrowing demand for services (Lancioni, 2005; Omachonu and Einspruch, 2010). During the current COVID-19 outbreak, some collaborative business-to-business marketing strategies are arising which include retailers sharing information about stock levels or pharmaceutical companies working together to develop a vaccine (Crick and Crick, 2020; Kang et al., 2020). Indeed, industrial marketing in health care contributes to increased productivity, to make the workforce more efficient, to healthier aging and to a reduction in sickness costs (Pilon and Hadjielias, 2017; Schiavone and Simoni, 2019). Good health industrial practices can support economic recovery and development (Bhargava et al., 2001; Bloom et al., 2004, 2019). Thus, efficient health-care industry systems - characterised by higher shares of health expenditures in the gross domestic product (GDP) and a large share of employment in the health sector - improve the health status of the population (Popescu et al., 2018).

Industrial marketing relations has notable power in public health-care contexts, based on its support of relationships 
amongst providers and customers and between providers and their suppliers (Wright and Taylor, 2005). Indeed, relationship marketing has been increased widely in the elevated value and risk industrial markets. On the other hand, as Anderson et al. (2019) attested, patients showed the necessity to take part in health-care delivery, impacting caregivers' roles. In this vein, the value co-creation in industrial marketing strategies within health-care contexts is conditioned on the relations amongst different actors having different positions (e.g. patients' families and health-care organisations).

Increasing expectations on the quality of health-care delivery have led to an increase in competitiveness in this sector, which continues to grow (Hwang and Christensen, 2008). The national health care spending in the US reached $\$ 3.81 \mathrm{tn}$ in 2019 ( $\$ 11,072$ per capita) and accounted for $17.9 \%$ of GDP. Looking ahead, health spending is projected to reach $\$ 6.19$ tn by 2028 , accounting for nearly one-fifth of GDP (OECD, 2020). Healthcare innovation - defined by Thakur et al. (2012) as the adoption of practices that help health-care practitioners work smarter, faster, better and more cost-effectively, ensuring safety and better outcomes for patients - has enabled a variety of organisations (such as hospitals and pharmaceutical companies) to innovatively create greater value for patients and all the stakeholders involved in the health-care industrial processes (Burns, 2012; Frow et al., 2016). The adoption of digital technologies has deeply changed the way health-care industrial processes and dynamics are managed, promoting cooperation amongst several health-care players such as manufacturers, distributors and medical service providers (Laurenza et al., 2018; Schiavone et al., 2020). Furthermore, third-party actors think about innovative practices of doing business in the health-care ecosystem for supporting the complex set of interconnections between different health-care actors (Spena and Cristina, 2019).

Digital transformation of the industrial practices in health care through broad and deep use of health information technology (HIT) has made services and processes more efficient, enabling national health systems and doctors to provide better quality and reduce drugs and medical devices costs and response times, with many benefits for patients and for users of health industrial practices in general (Agarwal et al., 2010). According to Thakur et al. (2012), HIT systems increase health-care efficiency and enable health-care organisations and individuals to achieve highly reliable performance in a dynamic and unpredictable environment. Advancement in health-care information technology facilitates the way doctors communicate with patients (Schiavone et al., 2020); it enables health-care practitioners to collect a wide range of patient demographic, clinical data and the development of integrated, accessible electronic health records (Miller et al., 2016; Wang et al., 2018a, 2018b). Furthermore, HIT enables health organisations and systems to offer their diagnostic and treatment products/services in a simpler and faster way (for example, via mobile Health apps and sensors, e-health and wearable devices) (Agarwal et al., 2010; Laurenza et al., 2018). Finally, it also favours the awareness of health-care amongst consumers through online forums and other health-care information systems (Thakur et al., 2012). In other words, health-care innovation and technology are improving (and prolonging) people's life by contributing to bending the cost curve in health care (Menon and Lee, 2000) and to enhancing health-care quality, efficiency and industrial performance in supply chain management (Chaudhry et al., 2006; De Vries and Huijsman, 2011; Devaraj et al., 2013).

The enormous changes brought by disruptive technologies in the health-care environment have made it necessary to develop new innovative business models (Hwang and Christensen, 2008), with the shift from volume-oriented strategies to valueoriented strategies (Chen et al., 2016) and from outcome-based approaches to system-based approaches (Buttigieg et al., 2016). Although health care has advanced tremendously over the past two decades, the COVID-19 pandemic has highlighted that there is still a long way to go to improve health-care systems across the world. The COVID-19 pandemic is changing the future of the health care industry by reshaping health systems and restructuring health-care organisations, which are accelerating their digital transformation roadmaps and are preparing themselves to launch new initiatives when the crisis passes (Crick and Crick, 2020).

\subsection{Health-care industry and economic growth nexus in OECD countries}

Nowadays, industrial marketing in health care has an important economic impetus as an employer (the health-care workforce has increased over the years despite the general decline in employment due to the economic crisis), as well as in the construction and service sectors, indeed, federal governments have invested significantly in building infrastructure able to manage business negotiations between health actors through industrial approaches for supply-chain management, market access and drugs delivery (Hwang and Christensen, 2008; Pilon and Hadjielias, 2017). For instance, recent scholars established the important role of market access strategies to have the marketing authorisation and better supply conditions for pharmaceutical products (e.g. drugs or medical devices) to enter in a new market (Smith, 2012; Toumi, 2017; Koçkaya and Wertheimer, 2018; Schiavone and Simoni, 2019). On the other hand, hospitals and specialised medical centres and are now equipped with state-of-technology medical equipment (Wright et al., 2019).

The impact of health on economic growth has attracted considerable attention from social scientists and economists over the years. A series of research studies have indicated the close links between economic status and a whole host of wellbeing indicators including health status and industrialisation (Gupta and Mitra, 2004; Bloom et al., 2004; Casasnovas, 2007; Ogasawara, 2018). In this vein, Yildirim and Calıskan (2020) explored the sustainable perspective to examine the influence of health on economic growth. This study proved that higher life expectations can impact economic growth positively in countries with worse or low health status. Another recent study demonstrated that health human capital significantly impacts long-run economic growth (Sarpong et al., 2020). Most of these studies consider health practices to be a crucial aspect of human capital, and therefore, a critical ingredient of economic growth. Bloom et al. (2004) reveal that good health industrial practices has a positive, sizable and statistically significant effect on economic growth. The authors find that a one-year improvement in a population's life expectancy contributes to a $4 \%$ increase in output. Similarly, Well (2007) has shown the positive impact of the health industry on GDP per capita, stressing how eliminating health differences between 
rich and poor countries would reduce the variance of logarithmic GDP per worker by $9.9 \%$ and reduce. Using life expectancy as a broad measure of population health, Bhargava et al. (2001) measure its impact on economic growth rates for low-income countries committed in performing efficient and effective health industrial practices. Results showed significant effects of population health on economic growth. For the poorest countries, a $1 \%$ change in life expectancy was associated with an approximate $0.05 \%$ increase in growth rate.

Different scholars have confirmed that an increase in public health expenditure has the power of improving health industrial outcomes and economic growth in developing countries (Olisakwe, 2019). In a recent study, Olisakwe (2019) analyses the empirical evidence of a unidirectional causality that linkages amongst public health expenditure, infant mortality rate and economic growth in Nigeria. Other studies focussing on OECD countries show similar results. Joumard et al. (2010), for example, evaluate the performance of the health industry in OECD countries to discover its strengths and weaknesses and propose the adoption of best policy practices to increase the efficiency of health spending. Berger and Messer (2002) use data from 20 OECD countries to explore the effects of factors such as the public financing of health expenditures and insurance coverage on health outcomes. The authors reveal that health outcomes depend on the mix of health-care expenditures and the type of health insurance coverage for industrial practices; reduced mortality rates are associated with increases in inpatient and ambulatory insurance coverage whilst an increase in mortality rates is associated with increases in the publicly financed share of health expenditures.

Using data from 17 OECD countries, Kim and Lane (2013) find similar results. Specifically, the authors find that government health expenditure in industrial practices negatively affects infant mortality and positively affects life expectancy at birth. Wang (2015) confirms that an increase in health expenditure leads to better economic performance in OECD countries. In the same vein, Weil (2014) examines the relationship between the health industry and economic growth, confirming that income per capita is highly correlated with people's health. As already demonstrated in past studies, the author attributes the relationship between health and income to the fact that healthier individuals live longer and are more productive. Using 2004-2013 annual data from 22 countries, Wang et al. (2018a, 2018b) empirically examine the effects of perceived health status (i.e. "health shocks") on economic growth, health expenditure and life insurance consumption. The authors find that at low-income levels perceived health status can make economic growth stagnant and reduce health expenditures.

\section{Hypotheses development}

The health system, as an industry, is a key component of the economy and one of the principal sources of employment in most countries. Apart from creating jobs, the industrial dynamics in health-care context, by its very nature, contributes to the economy by influencing the competitiveness and innovative marketing strategies in the global pharmaceutical industry and consequently, the discovery of new pharmaceutical and medical devices. Sorely tried by the events that have come to define the recent history, health-care organisations and pharmaceutical industries have shown their ability to promptly address the large and urgent demand for vaccines and treatment therapies for patients suffering from the COVID-19. The health industry also affects the economy through cross-border health care and remote provision of services, its influence on the mobility of patients, professionals and services and its association with the educational sector in the form of clinical training and life sciences (Ried and Rau, 2017). Earlier research has shown that the health industry affects countries' economic growth whilst increasing the wellbeing of individuals (Piabuo and Tieguhong, 2017). This is even more true when it comes to developing countries, where the development of a country's health system is closely related to the economic and social development of the country itself (Olisakwe, 2019).

In the context of emerging economies, a recent African study found a positive association between health expenditures and economic growth (Somé et al., 2019). To the best of our knowledge, no earlier study linked the industrial dynamics in health-care context - intended as the set of factors that constitute them and determine their development, producing certain effects - to countries' economic growth.

Therefore, the debate on how the health-care industrial dynamics affect economic growth is unresolved. Hence, we hypothesize the following:

H1. There is a positive association between the effectiveness and efficiency of the health-care industry and the economic growth of the countries analysed.

Health systems also affect the economy indirectly, helping to improve individuals' health status. Several studies have shown that individuals in better health enjoy improved opportunities for economic participation and contribution through a greater presence in the labour market. Healthier individuals, therefore, may also enjoy greater earning opportunities compared to their less healthy counterparts. A study from Dwomoh et al. (2013), for example, reveals that health and safety policies put in place by Ghana's timber companies have a positive impact on employees' performance by reducing the number of accidents and injuries and helping them achieve their targets.

Another important benefit of the industrial dynamics in health-care context is afforded by the PHI, which provides primary financial protection for workers and their families (Sekhri and Savedoff, 2005). PHI schemes can be valuable tools to complement public health-financing options targeted to programmes covering poor and vulnerable populations.

Finally, the industrial practices in health-care context make an important contribution to societal well-being by delivering high-quality health services and at an affordable cost. Quality health services not only reduce mortality and prevent human suffering, but they also improve the quality of life and ensure healthier societies.

In light of the above, we hypothesize the following:

H2. There is a positive association between the effectiveness and efficiency of the health-care industry and the overall health status of the population. 


\section{Data and methodology}

In this section, we provide data on growth (GDP), foreign direct investment (FDI), population growth, urban population, health status, expenditures on health, industrial and infrastructure, in 29 selected OECD countries [1]. The countries' selection was made considering the availability of data relating to the variables of interest. Using panel regressions, we investigate the impact of the health-care industry measured in terms of health status, health expenditure, sales on pharmaceutical products, number of persons working in the health care and social work and the coverage by PHI on the economic growth and status of the health of the analysed countries.

We use as a dependent variable the economic growth, measured by the annual percentage growth rate of the GDP ( $G D P G)$ and health status ( $H S$ ) with considering the crude birth rate, crude death rate and life expectancy. We look at economic growth and health status (HS) in a simultaneous framework, suggesting that they influence each other following the two-way causation thesis (Gupta and Mitra, 2004). This thesis suggests that better health outcomes help boost economic growth by increasing employment opportunities and the ability to earn, respectively. According to Stark (1999), the growth performance of the economy should improve with an increase in the health of the population, which raises earnings, and therefore, consumer spending. On the other hand, greater economic growth generates a greater volume of resources to be spent on activities related to development and well-being, including health.

As independent variables, we use the FDI, Population growth $(P O P G)$, health status (HS), Expenditures on health per capita $(H E X P C)$, percentage of population residing in urban areas $(U R B A N)$, Percentage of the GDP originated from manufacturing (IDUS), Percentage of the GDP originated from manufacturing (IDUS), Percentage of the GDP originated from transport service (INFRA), Sales of pharmaceutical products on the domestic market (PHMR), Number of persons (headcount) working in health care and social work (HEMP) and The percentages of population covered by PHI (PHICOV).

Data on used variables were collected from the World Bank database and OECD database. The data sequence comprises annual data from 2000 to 2019. Data sources and variables are presented in Table 1.

Table 2 provides descriptive statistics related to the variables used in this research. In particular, the average health expenditure in studies countries is almost $\$ 2,779 \mathrm{~m}$. Furthermore, health expenditure on average has a portion of GDP, which is equal to $8.3 \%$. The population growth in OECD selected countries in 20 years is $0.5 \%$.

With Gupta and Mitra (2004) research in mind and to analyse and determine the relationship between health status and economic growth in selected OECD countries, we applied the following models:

$$
\begin{aligned}
& G D P G_{i t}=\alpha+\beta_{1} F D I_{i t}+\beta_{2} P O P G_{i t}+\beta_{3} I M R_{i t} \\
& +\beta_{4} U R B A N_{i t}+\beta_{5} I N D U S T_{i t}+\beta_{6} I N F R A_{i t} \\
& +\beta_{7} H E X P_{i t}+\beta_{8} P H M R_{i t}+\beta_{9} H E M P_{i t} \\
& +\beta_{9} \text { PHICOV }{ }_{i t}+\tau_{t}+\varepsilon_{i t}
\end{aligned}
$$

\begin{tabular}{|c|c|c|c|}
\hline Variable & Symbol & Description & $\begin{array}{l}\text { Data } \\
\text { sources }\end{array}$ \\
\hline GDP per capita & $G D P$ & $\begin{array}{l}\text { Gross domestic product } \\
\text { divided by midyear } \\
\text { population }\end{array}$ & $\begin{array}{l}\text { World } \\
\text { Bank }\end{array}$ \\
\hline GDP growth & GDPG & $\begin{array}{l}\text { The annual percentage } \\
\text { growth rate of GDP per capita } \\
\text { based on constant local } \\
\text { currency }\end{array}$ & $\begin{array}{l}\text { World } \\
\text { Bank }\end{array}$ \\
\hline $\begin{array}{l}\text { Foreign direct } \\
\text { investment }\end{array}$ & FDI & $\begin{array}{l}\text { Direct investment equity } \\
\text { flows given by the sum of } \\
\text { equity capital, reinvestment } \\
\text { of earnings and other capital }\end{array}$ & $\begin{array}{l}\text { World } \\
\text { Bank }\end{array}$ \\
\hline $\begin{array}{l}\text { Annual } \\
\text { population } \\
\text { growth rate }\end{array}$ & POPG & $\begin{array}{l}\text { The exponential rate of } \\
\text { growth of midyear population } \\
\text { from year t-1 to } t \text {, expressed } \\
\text { as a percentage }\end{array}$ & $\begin{array}{l}\text { World } \\
\text { Bank }\end{array}$ \\
\hline Health status & $H S$ & $\begin{array}{l}\text { Crude birth rate, crude death } \\
\text { rate and life expectancy }\end{array}$ & $\begin{array}{l}\text { World } \\
\text { Bank }\end{array}$ \\
\hline Urbanisation & URBAN & $\begin{array}{l}\text { Percentage of population } \\
\text { residing in urban areas }\end{array}$ & $\begin{array}{l}\text { World } \\
\text { Bank }\end{array}$ \\
\hline Industrialisation & INDUST & $\begin{array}{l}\text { Percentage of the GDP } \\
\text { originated from } \\
\text { manufacturing }\end{array}$ & $\begin{array}{l}\text { World } \\
\text { Bank }\end{array}$ \\
\hline Infrastructures & INFRA & $\begin{array}{l}\text { Percentage of the GDP } \\
\text { originated from transport } \\
\text { service }\end{array}$ & $\begin{array}{l}\text { World } \\
\text { Bank }\end{array}$ \\
\hline $\begin{array}{l}\text { Health } \\
\text { expenditure }\end{array}$ & $H E X C P$ & $\begin{array}{l}\text { Expenditures on health per } \\
\text { capita }\end{array}$ & OECD \\
\hline $\begin{array}{l}\text { Pharmaceutical } \\
\text { sales }\end{array}$ & PHMR & $\begin{array}{l}\text { Sales of pharmaceutical } \\
\text { products on the domestic } \\
\text { market }\end{array}$ & OECD \\
\hline $\begin{array}{l}\text { Health } \\
\text { workforce }\end{array}$ & HEMP & $\begin{array}{l}\text { Number of persons (head } \\
\text { count) working in health care } \\
\text { and social work }\end{array}$ & OECD \\
\hline $\begin{array}{l}\text { Private health } \\
\text { insurance } \\
\text { coverage }\end{array}$ & PHIVOC & $\begin{array}{l}\text { The percentages of } \\
\text { population covered by private } \\
\text { health insurance }\end{array}$ & OECD \\
\hline
\end{tabular}

Table 1 Description of variables and data sources

$$
\begin{aligned}
\text { IMR }_{i t}= & \alpha+\beta_{1} \text { GDP }_{i t}+\beta_{2} \text { POPG }_{i t}+\beta_{3} \text { URBAN }_{i t} \\
& +\beta_{4} \text { INDUST }_{i t}+\beta_{5} \text { INFRA }_{i t}+\beta_{6} \text { HEXP }_{i t} \\
& +\beta_{7} \text { PHMR }_{i t}+\beta_{8} \text { HEMP }_{i t}+\beta_{9} \text { PHICOV }_{i t} \\
& +\tau_{t}+\varepsilon_{i t}
\end{aligned}
$$

where: GDP represents the gross domestic product in the period $t, F D I$ represents the foreign direct investment, POPG represents the population growth, $H S$ represents the health status, $U R B A N$ represents the percentage of the population residing in urban areas, INDUS represents the percentage of the GDP originated from manufacturing, INFRA represents the percentage of the GDP originated from transport service and $H E X P C$ represents the health expenditure per capita, $P H M R$ represents the sales of pharmaceutical products on the domestic market, HEMP represents the number of persons 
Table 2 Summary statistics

\begin{tabular}{|c|c|c|c|c|c|}
\hline Variable obs. & $N$ & Mean & SD & Minimum & Maximum \\
\hline$G D P G$ & 580 & 0.02527 & 0.313848 & -0.14814 & 0.11888 \\
\hline$G D P$ & 580 & $33,322.13$ & $21,784.1$ & $3,119.566$ & $118,823.6$ \\
\hline FDI & 571 & $1,95 e+09$ & $3.11 e+10$ & $-2.92 e+11$ & $1,63 e+11$ \\
\hline POPG & 580 & 0.00533 & 0.008118 & -0.02258 & 0.026781 \\
\hline$H S$ & 551 & $-3.17 e-09$ & 1.339395 & -3.28079 & 3.533659 \\
\hline URBAN & 580 & 0.770545 & 0.115802 & 0.5075 & 0.9804 \\
\hline INDUS & 574 & 0.144814 & 0.04871 & 0.0395 & 0.2824 \\
\hline INFRA & 528 & 0.072066 & 0.06905 & 0.0014 & 0.3372 \\
\hline HEXP & 518 & $2,777.347$ & $1,945.03$ & 153.62 & $9,241.27$ \\
\hline PHMR & 486 & $6,559.414$ & $8,979.36$ & 66.4 & $50,587.1$ \\
\hline HEMP & 499 & $819,300.3$ & $1,112,595$ & 17,624 & $5,942,000$ \\
\hline PHICOV & 457 & 0.3087593 & 0.2996092 & 0 & 0.958 \\
\hline
\end{tabular}

(headcount) working in health care and social work and PHICOV represents the percentages of population covered by PHI.

Following Gupta and Mitra (2004), we build a collective measure of the health status (HS) by using three main indicators, namely, life expectancy and crude birth and death rates. Life expectancy is defined as the average number of years a population of a certain age would be expected to live, given a set of age-specific death rates in a given year. Crude death rate indicates the number of deaths occurring during the year, per 1,000 population estimated at midyear, whilst crude birth rate indicates the number of live births occurring during the year, per 1,000 population estimated at midyear.

These are better indicators of the overall health status of the population, as they are more reflective of the demographic changes taking place in the economy and are influenced by changes in health policy, including investment in health and health services.

To compute the health status (HS), we used the principal component analysis (PCA) - a dimensionality-reduction method used to reduce the number of variables of a data set, whilst preserving as much information as possible. This method allows reducing a large set of correlated variables into a smaller set of uncorrelated variables (called principal components) that are ordered so that the first few retain most of the variation present in all of the original variables (Stock and Watson, 2002).

Using the PCA, we reduced the original set of three health indicators (i.e. life expectancy and crude birth rate and crude death rate) to a smaller set of composite factors. As the PCA method explains the variations of the selected variables better than any other linear combination (Ang and McKibbin, 2007), by using it we avoid multicollinearity problems.

Following Naik (2017), to build the $H S$ we estimated the total variance clarified by the principal components for each country (we applied the PCA model for 29 countries). Following Gray (2017), we selected the value of the eigenvalue where it was calculated to be more than one and each principal component explained more than $70 \%$; we removed the other components with a value of less than one. By using the rotation method Varimax, we rotated the components with the objective of making them as simple as possible to interpret, establishing the preliminary eigenvalues linked with the appropriate components, then computed the $H S$.
Furthermore, we performed Parallel Analysis to ensure that the appropriate number of components are selected. We ran "fapara" in Stata to use the Parallel Analysis, we choose the eigenvalues in the PCA column greater than the average eigenvalues in the parallel analysis column. The results of the parallel analysis confirm the appropriate number of selected components.

We assumed that there is an effect between variables in the selected countries, so we use the panel data analysis technique. In this technique, there is either a fixed effect or a random effect between the independent variables and the dependent variable. The fixed-effects model produces a constant estimate, but in contrast, the Hausman test determines an appropriate model. Panel data makes it possible to analyse the series of times and different countries. Therefore, estimating panel data increases estimation efficiency by analysing the data, increasing the degree of freedom and reducing the collinearity between variables. Another advantage of this technique is that it allows for the analysis of data by using many variables at the same time in a time series and selected countries (Petersen, 2004).

\section{Results}

We first used fixed-effect panel regression to find the relationship between the industrial dynamics in health-care context and the underlying economic growth in the selected countries better. The indicators that we tried to identify are the following: economic growth, FDI, health variables and population variables. Table 3 represents the results of the fixedeffect panel regression, which show that FDI has a direct and significant relationship with economic growth. This means that, by increasing $F D I$, economics provides more products to more individuals and groups in society. The fixed-effect panel regression specially the first column shows the positive impact of the health expenditure on $G D P$, also the coefficients are positive.

The results indicate a meaningful relationship between the health industrial practices and economic growth in $H S$ and a clear positive relationship between the different aspects of the economic development (such as the population) and economic activity (such as production) with economic growth. These results also confirm and expand the extant industrial marketing literature (Anderson et al., 2019; Schiavone and Simoni, 2019; Crick and Crick, 2020; Kang et al., 2020) by showing a nexus between the industrial marketing dynamics of health-care 
Table 3 Results of statistical analysis

\begin{tabular}{|c|c|c|c|c|}
\hline $\begin{array}{l}\text { Variable } \\
\text { (Dependent variable) }\end{array}$ & $\begin{array}{l}\text { Fixed-effect } \\
\text { GDPG }\end{array}$ & $\begin{array}{l}\text { Fixed-effect } \\
\text { HS }\end{array}$ & $\begin{array}{c}\text { Random-effect } \\
\text { GDPG }\end{array}$ & $\begin{array}{c}\text { Random-effect } \\
\text { HS }\end{array}$ \\
\hline$G D P$ & & $0.09 * *(0.03)$ & & $0.06 *(0.03)$ \\
\hline FDI & $0.0003^{* *}(0.04)$ & $0.065^{* *}(0.03)$ & $0.0002 * *(0.003)$ & $0.062 *(0.01)$ \\
\hline POPG & $0.762^{* *}(0.28)$ & $0.131 * *(0.35)$ & $0.719 * *(0.24)$ & $0.24^{* *}(0.46)$ \\
\hline HS & $0.019^{* *}(0.08)$ & & $0.003^{* *}(0.02)$ & \\
\hline URBAN & $0.114^{*}(0.08)$ & $0.66 * *(0.06)$ & $0.04^{* *}(0.02)$ & $2.97^{* *}(0.78)$ \\
\hline INDUST & $0.525^{* *}(0.09)$ & $-0.39 * *(0.34)$ & $0.37^{* *}(0.05)$ & $-0.28^{* *}(0.31)$ \\
\hline INFRA & $0.031^{*}(0.02)$ & $0.63^{* *}(0.28)$ & $0.024 *(0.01)$ & $0.32^{* *}(0.29)$ \\
\hline HEXP & $0.02^{*}(0.02)$ & $0.01^{* *}(0.01)$ & $0.02 * *(0.01)$ & $0.01 * *(0.01)$ \\
\hline PHMR & $0.03(0.01)$ & $0.01^{* *}(0.01)$ & $0.03(0.01)$ & $0.01 *(0.01)$ \\
\hline HEMP & $0.071^{* *}(0.01)$ & $0.054^{* *}(0.01)$ & $0.02 * *(0.01)$ & $0.011^{* *}(0.01)$ \\
\hline \multirow[t]{2}{*}{ PHICOV } & $0.052^{*}(0.01)$ & $0.81^{* *}$ & $0.018 *(0.01)$ & $0.80^{* *}(0.24)$ \\
\hline & & 0.28 & & \\
\hline CONS & $0.121^{* *}(0.02)$ & $0.095^{* *}(0.03)$ & $0.018^{* *}(0.01)$ & $0.059^{* *}(0.02)$ \\
\hline Number of groups & 29 & 29 & 29 & 29 \\
\hline Number of observations & 329 & 329 & 329 & 329 \\
\hline$p$-value & $0.000^{* *}$ & $0.00^{* *}$ & $0.00^{* *}$ & $0.00^{* *}$ \\
\hline Hausman test & $0.00^{* *}$ & $0.00^{* *}$ & & \\
\hline
\end{tabular}

context and economic growth in the selected OECD countries. The industrial practices in health-care context show the collaborations amongst the actors along the value chain and attest to show how, in the long run, the quality of health-care delivery have led to an increase in economic growth and health status of the population. This improvement is viewed as the expansion of networks of users (e.g. patients, decision makers, etc.) who are continuously involved.

Urbanisation and industrialisation are seen to influence growth positively. Industrialisation is seen to have a negative effect on health status (HS). The health variables show a positive impact on economic growth; employment in the health-care industry increases the economic growth and health status, as well as the percentages of the population covered by PHI. Also, in line of Muratoglu's (2017) studies increasing pharmaceutical sales boosts the economic growth.

Table 3 shows the results of the main panel regression, specifically, the results of fixed effects and the consequences of random effects. The second column shows the main $H S$ as the dependent variable. Also, the results of the random-effects model indicate an increase in the health expenditure on health status (HS). The results of the fixed effects are also similar. In empirical analyses, the standard issue of choice between fixed and random effect estimates (Petersen, 2004) is resolved by using the Hausman test, the results of which (shown in the last row of Table 3) suggest that a fixed effects estimator is more appropriate.

The results of the second column show significant and positive effects of health expenditure, pharmaceutical sales and employment in health care on economic growth. The results confirm that health expenditure has a positive and significant impact on HS. Concerning the existence of increasing health expenditure, an increase in one aspect of the health system increases the $H S$. For example, a $1 \%$ increase in health care spending over an annual period can impact a $1 \%$ increase in $H S$. Furthermore, a $1 \%$ increase in employment in health care can produce a $5.4 \%$ increase in $H S$. These results confirm the results of previous studies that have shown a significant relationship between these variables. The results in Table 3 column one - also show that population growth is significant. The total population growth ratio has a coefficient equal to 0.762 . A $1 \%$ increase in the ratio can thus, lead to a $76 \%$ percent increase in growth rate. The urban variable is high the same as the population ratio coefficient, which is 0.114 ; results prove once more the urbanisation leads to the economic growth in the selected countries. Contrariwise, the results of the second column show that population growth has a negative impact on health status. The industry and infrastructure variables support this conclusion, increasing the industrial activities and transport activities will harm for health status in the selected countries. Finally, increasing the expenditure on health, employment in health care and increasing the pharmaceutical market will lead to economic growth and better health status. According to Gupta and Mitra (2004), health expenditure is one of the important factors for economic growth and health status.

Finally, we run the robustness check to control coefficient estimates' behaviour for country effects (Table 4). Following Lu and White (2014), we use the "Checkrob" command on Stata. Our findings show that the coefficients of independent variables do not change much and their impacts on GDP remain the same. However, FDI and the population covered by PHI (PHICOV) have a robust positive impact on health status (HS). On the other hand, industrialisation (INDUST) has a robust and negative impact on health status (HS). However, other coefficients do not change much of their impact on $H S$.

\section{Discussion}

These results try to explore the existing literature through deepening of the studies that regard the industrial dynamics within health-care context and their impact on economic growth (Wright and Taylor, 2005; Anderson et al., 2019; Yildirim and Calıskan, 2020; Crick and Crick, 2020). 
Table 4 Results of robustness check by country on the selected model

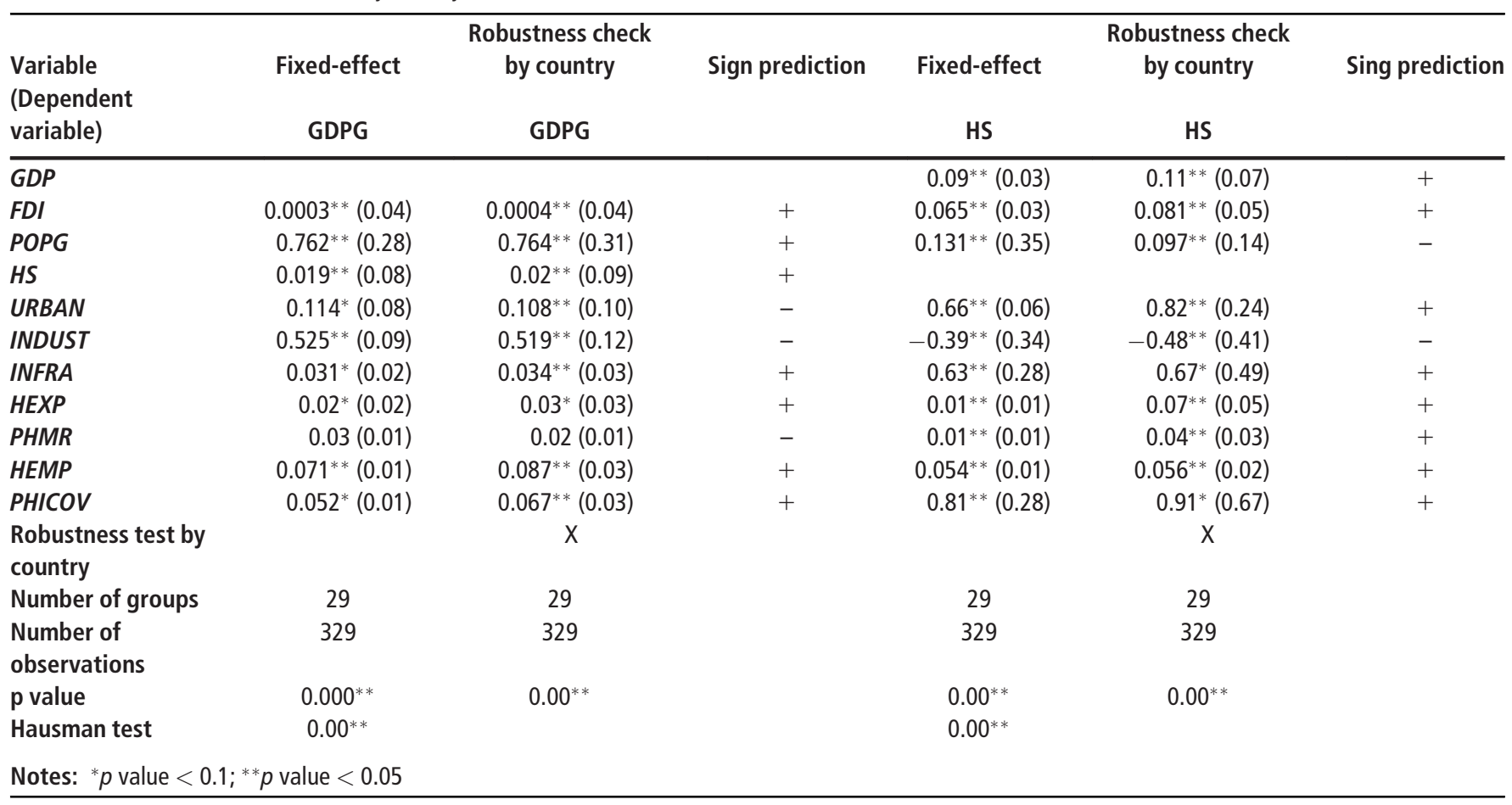

We attempt to generate some empirical foundations. The research introduces the main issues within the industrial marketing literature and after focusses on the recent studies to explore industrial practice that organise the relationships in a context such as health care. Our research attested that industrial performance in health-care context is tied to the reliability and efficiency of processes; indeed, they are realised by a series of phases, starting from the analytic phase, up to the processing of pathology and the hospitalisation. These activities are faced by different actors (e.g. physicians, physiotherapists and nurses) and not all the steps may be clinical; in this vein, the fragmentation and heterogeneity of the health-care delivery process lead to a multidisciplinary industrial approach. For those aspects, industrial dynamics might be improved, not only by focussing on each delivery phase but also by enhancing the level of coordination along the health-care value chain.

Thus, the present study offers a knowledge contribution to the industrial marketing studies about the impact of industrial dynamics on economic growth and health status that could speed up and facilitate the innovation care process of the health-care industry and the time to market for drugs and medical devices in this context. The adoption of an emergent innovation ecosystem in favour of a coordinated network of industrial collaboration amongst different hospitals, physicians and workers emerge as a crucial issue to improve different dynamics for economic growth and health status in our selected OECD countries. Therefore, the network management should deal with a difficult trade-off between the increasing integration of actors and the increased complexity of business process analysis. Besides, the degree of complexity is related to an abundance of factors, such as new required expertise, the running costs of innovative infrastructure for the health-care industry and hardware and software maintenance.

\section{Conclusions and implications}

Our exploratory study offers theoretical implications for the emerging stream of literature about the industrial dynamics in health-care context (Anderson et al., 2019; Schiavone and Simoni, 2019; Crick and Crick, 2020) and their impact on economic growth and health status (Buttigieg et al., 2016; Bloom et al., 2019; Yildirim and Calıskan, 2020) by exploring particular form of industrial marketing approaches (e.g. market access) and by using data on growth $(G D P), F D I$, population growth, urban population, health status (HS), expenditures on health, industrial and infrastructure, in 29 selected OECD countries.

Health-care organisations are rethinking their industrial approaches to search for a competitive advantage in this complex context. We also show managerial implications for health-care practitioners about the fundamental relationship amongst different actors (e.g. pharmaceutical companies, payers, decision makers and key account managers). The aim is to adopt business-to-business marketing strategies capable of ensuring a lasting presence on the market and an adequate level of economic growth for population. This industrial strategy should be a fundamental piece of all the functional divisions of the pharmaceutical companies that should invest within the entire supply chain management. Our research may be the starting point to plan new industrial strategies to investigate the necessity to create shared practices between the various stakeholders involved in industrial markets to increase the time to market for drugs and medical devices and an adequate level of sustainability of the entire health-care supply chain.

Drawing on the above-reported results, some implications for future research can be developed. The improvement of industrial dynamics in health-care context could represent a way to implement efficient co-working collaborations to 
advance competitive advantages and economic growth for different countries. A newsworthy implication for scholars of industrial marketing is that health-care industry gathers a rather unique scale of adjoining business area (e.g. pharmaceutics and e-health) whose main and different stakeholders could constantly participate through long-term industrial relationships. Indeed, we illustrated the positive association between the effectiveness and efficiency of the health-care industry and the overall health status of the population, which reduced bureaucratical health-care processes and propose flexible collaboration amongst the healthcare value chain.

A reflection on the evolution of the collaborative business-tobusiness marketing strategies in health care is also interesting. This reflection is related to the practice-oriented implications for industrial marketers and it is based on two points. Firstly, this type of collaboration and relationships amongst different actors (buyer/supplier and decision makers) has considerable influence in public health-care decisions to speed up the time to market and economic growth and to assure effectiveness and efficiency of the industrial processes. Secondly, it is tangible that the positive effect of industrial health practices more patient-oriented improves the overall health status of the population. These are evidence of the close correlation between the industrial marketing performance and the economic growth to sustain the health level of society and its economic development (Wright and Taylor, 2005; Anderson et al., 2019; Yildirim and Calıskan, 2020; Crick and Crick, 2020).

Finally, policymakers across the globe have started to look at HIT as a key tool for making health-care industrial performance more affordable, safer and more accessible. In recent years, health status has boosted global economic growth, but health-related variables need more advancement, as noted in this study. The costs of a poor health care system can increase costs in society. In such a turbulent global scenario, reconsidering the role played by the health system in society is essential to ensure the economic recovery of the countries. Moreover, a poor health system not only damages the people concerned but also represent a cost to society, reducing its economic growth. Studies, including ours, have shown that the higher health status increased the economic growth.

Using recent data from selected OECD countries over the period 2000-2019, we investigate the dynamics of health-care industrial markets and their impact on economic growth and health status. We addressed the poor health status issue from several different perspectives, including expenditure on health, pharmaceutical market, employment in health-care sector and industrial activities. In line with the literature, our results confirm the positive effect of expenditure on health on economic growth. Moreover, more performing sales channels in the commercial sector of the pharmaceutical market, as well as an increase in the health-care workforce and in PHI coverage lead to higher health status and economic growth. Therefore, the study suggests policymakers to focus on these different industrial aspects of the health-care system. Health status can be results of the expenditure on health on the long-term. The empirical findings of this research emphasise the urgent need for policymakers to implementing industrial changes in the economic and social structure to increase the level of health status. Addressing the problem of health-care delivery requires actions aimed at ensuring increasing industrial investment on the health system to improve the economic growth, the wellbeing and the patients' quality of life.

\section{Note}

1 Selected OECD countries: Australia, Austria, Belgium, Canada, Chile, Czech Republic, Denmark, Estonia, Finland, Germany, Greece, Hungary, Iceland, Israel, Italy, Republic of Korea, Latvia, Lithuania, Luxemburg, The Netherlands, New Zealand, Norway, Portugal, Slovak Republic, Slovenia, Spain, Sweden, Turkey and the UK.

\section{References}

Agarwal, R., Gao, G., DesRoches, C. and Jha, A.K. (2010), "Research commentary - the digital transformation of healthcare: current status and the road ahead", Information Systems Research, Vol. 21 No. 4, pp. 796-809.

Anderson, S., Rayburn, S.W. and Sierra, J.J. (2019), "Future thinking: the role of marketing in healthcare", European Fournal of Marketing, Vol. 53 No. 8, pp. 1521-1545.

Ang, J.B. and McKibbin, W.J. (2007), "Financial liberalization, financial sector development and growth: evidence from Malaysia", fournal of Development Economics, Vol. 84 No. 1, pp. 215-233.

Bedir, S. (2016), "Healthcare expenditure and economic growth in developing countries", Advances in Economics and Business, Vol. 4 No. 2, pp. 76-86.

Berger, M.C. and Messer, J. (2002), "Public financing of health expenditures, insurance, and health outcomes", Applied Economics, Vol. 34 No. 17, pp. 2105-2113.

Bhargava, A., Jamison, D.T., Lau, L.J. and Murray, C.J. (2001), "Modeling the effects of health on economic growth", Fournal of Health Economics, Vol. 20 No. 3, pp. 423-440.

Bloom, D.E., Canning, D. and Sevilla, J. (2004), "The effect of health on economic growth: a production function approach", World Development, Vol. 32 No. 1, pp. 1-13.

Bloom, D.E., Canning, D., Kotschy, R., Prettner, K. and Schünemann, J.J. (2019), "Health and economic growth: reconciling the micro and macro evidence (No. w26003)", National Bureau of Economic Research.

Burns, L.R. (Ed.) (2012), The Business of Healthcare Innovation, Cambridge University Press, Cambridge.

Buttigieg, S.C., Prasanta, D. and Gauci, D. (2016), "Business process management in health care: current challenges and future prospects", Innovation and Entrepreneurship in Health, Vol. 3, pp. 1-13.

Casasnovas, G.L., Rivera, B. and Currais, L. (Eds) (2007), Health and Economic Growth: findings and Policy Implications, MIT Press, Cambridge, MA.

Chaudhry, B., Wang, J., Wu, S., Maglione, M., Mojica, W., Roth, E., Morton, S.C. and Shekelle, P.G. (2006), "Systematic review: impact of health information technology on quality, efficiency, and costs of medical care", Annals of Internal Medicine, Vol. 144 No. 10, pp. 742-752.

Chen, C.T., Ackerly, D.C. and Gottlieb, G. (2016), "Transforming healthcare delivery: why and how 
accountable care organizations must evolve", fournal of Hospital Medicine, Vol. 11 No. 9, pp. 658-661.

Crick, J.M. and Crick, D. (2020), "Coopetition and COVID19: collaborative business-to-business marketing strategies in a pandemic crisis", Industrial Marketing Management, Vol. 88, pp. 206-213.

De Vries, J. and Huijsman, R. (2011), "Supply chain management in health services: an overview", Supply Chain Management: An International fournal, Vol. 16 No. 3, pp. 159-165.

Devaraj, S., Ow, T.T. and Kohli, R. (2013), "Examining the impact of information technology and patient flow on healthcare performance: a theory of swift and even flow (TSEF) perspective", Fournal of Operations Management, Vol. 31 No. 4, pp. 181-192.

Dwomoh, G., Owusu, E.E. and Addo, M. (2013), "Impact of occupational health and safety policies on employees' performance in the Ghana's timber industry: evidence from lumber and logs limited", International fournal of Education and Research, Vol. 1 No. 12, pp. 1-14.

Erdil, E. and Yetkiner, I.H. (2004), “A panel data approach for income-health causality", in Yfantopoulos, J.N. (Ed.), The Economics of Health Reforms, Chapter 38, Working Papers FNU-47, Research unit Sustainability and Global Change, Hamburg University, revised Apr 2004, pp. 701-724, ISBN: 960-88672-0-7.

Frow, P., McColl-Kennedy, J.R. and Payne, A. (2016), "Cocreation practices: their role in shaping a health care ecosystem", Industrial Marketing Management, Vol. 56, pp. 24-39.

Gray, V. (Ed.) (2017), Principal Component Analysis: methods, Applications, and Technology, Nova Science Publishers.

Gupta, I. and Mitra, A. (2004), "Economic growth, health and poverty: an exploratory study for India", Development Policy Review, Vol. 22 No. 2, pp. 193-206.

Huang, H., Leone, D., Caporuscio, A. and Kraus, S. (2020), "Managing intellectual capital in healthcare organizations. A conceptual proposal to promote innovation", fournal of Intellectual Capital, Vol. 22 No. 2, pp. 290-310.

Hwang, J. and Christensen, C.M. (2008), "Disruptive innovation in health care delivery: a framework for businessmodel innovation", Health Affairs, Vol. 27 No. 5, pp. 1329-1335.

Jamaludin, N.H., Habidin, N.F., Shazali, N.A., Ali, N. and Khaidir, N.A. (2013), "Exploring sustainable healthcare service and sustainable healthcare performance: based on Malaysian healthcare industry", fournal of Sustainable Development Studies, Vol. 3 No. 1.

Joumard, I. André, C. and Nicq, C. (2010), "Health care systems: efficiency and institutions", OECD Economics Department Working Paper No. 769, available at: https://ssrn.com/abstract= 1616546 or http://dx.doi.org/10.2139/ssrn.1616546

Kang, J., Diao, Z. and Zanini, M.T. (2020), "Business-tobusiness marketing responses to COVID-19 crisis: a business process perspective", Marketing Intelligence \& Planning, Vol. 39 No. 3, pp. 454-468.

Kim, T.K. and Lane, S.R. (2013), "Government health expenditure and public health outcomes: a comparative study among 17 countries and implications for US health care reform", American International fournal of Contemporary Research, Vol. 3 No. 9, pp. 8-13.

Koçkaya, G. and Wertheimer, A. (Eds) (2018), Pharmaceutical Market Access in Developed Markets, SEEd medical publishers, Torino, Italy.

Lancioni, R. (2005), "Pricing issues in industrial marketing", Industrial Marketing Management, Vol. 34 No. 2, pp. 111-114.

Laurenza, E., Quintano, M., Schiavone, F. and Vrontis, D. (2018), "The effect of digital technologies adoption in healthcare industry: a case-based analysis", Business Process Management fournal, Vol. 24 No. 5, pp. 1124-1144.

Lee, S.M., Lee, D. and Schniederjans, M.J. (2011), "Supply chain innovation and organizational performance in the healthcare industry", International fournal of Operations $\mathcal{E}$ Production Management, Vol. 31 No. 11, pp. 1193-1214.

Lu, X. and White, H. (2014), "Robustness checks and robustness tests in applied economics", Fournal of Econometrics, Vol. 178, pp. 194-206.

Menon, N.M. and Lee, B. (2000), "Cost control and production performance enhancement by IT investment and regulation changes: evidence from the healthcare industry", Decision Support Systems, Vol. 30 No. 2, pp. 153-169.

Miller, B.J., Moore, D.W. and Schmidt, J.C. (2016), "Telemedicine and the sharing economy: the 'Uber' for healthcare", The American fournal of Managed Care, Vol. 22 No. 12, pp. e420-e422.

Muratoglu, G. (2017), "Does pharmaceutical industry boost economic growth? A competitiveness-related approach", Fournal of Yaşar University, Vol. 12 No. 48, pp. 296-314.

Naik, G.R. (Ed.) (2017), Advances in Principal Component Analysis: Research and Development, Springer.

OECD (2020), "Health spending (indicator)", available at: http://dx.doi.org/10.1787/8643de7e-en (accessed 21 October 2020).

Ogasawara, K. (2018), "Health and education during industrialization: evidence from early twentieth century Japan", International Fournal of Educational Development, Vol. 61, pp. 40-54.

Olisakwe, O. (2019), "Public health expenditure, economic growth and health outcomes in Nigeria", Public Health, Vol. 6 No. 1, pp. 23-32.

Omachonu, V.K. and Einspruch, N.G. (2010), "Innovation in healthcare delivery systems: a conceptual framework", The Innovation fournal: The Public Sector Innovation fournal, Vol. 15 No. 1, pp. 1-20.

Petersen, T. (2004), Analyzing Panel Data: Fixed-and RandomEffects Models, Sage, London, pp. 331-345.

Piabuo, S.M. and Tieguhong, J.C. (2017), "Health expenditure and economic growth - a review of the literature and an analysis between the economic community for Central African states (CEMAC) and selected African countries", Health Economics Review, Vol. 7 No. 1, p. 23.

Pilon, F. and Hadjielias, E. (2017), "Strategic account management as a value co-creation selling model in the pharmaceutical industry", fournal of Business E Industrial Marketing, Vol. 32 No. 2, pp. 310-325.

Popescu, M.E., Militaru, E., Cristescu, A., Vasilescu, M.D. and Maer Matei, M.M. (2018), "Investigating health systems in the European union: outcomes and fiscal sustainability", Sustainability, Vol. 10 No. 9, p. 3186. 
Ried, W. and Rau, R.H. (2017), "Cross-border health care in the European union: evaluation of different financing arrangements", Engineering Management in Production and Services, Vol. 9 No. 2, pp. 8-20.

Sarpong, B., Nketiah-Amponsah, E. and Owoo, N.S. (2020), "Health and economic growth nexus: evidence from selected Sub-Saharan African (SSA) countries", Global Business Review, Vol. 21 No. 2, pp. 328-347.

Schiavone, F. and Simoni, M. (2019), "Strategic marketing approaches for the diffusion of innovation in highly regulated industrial markets: the value of market access", fournal of Business E̋ Industrial Marketing, Vol. 34 No. 7, pp. 1606-1618.

Schiavone, F., Leone, D., Sorrentino, A. and Scaletti, A. (2020), "Re-designing the service experience in the value cocreation process: an exploratory study of a healthcare network", Business Process Management Fournal, Vol. 26 No. 4, pp. 889-908.

Schultz, T.P. (2005), Productive Benefits of Health: Evidence from Low-Income Countries. Health and Economic Growth: Findings and Policy Implications, MIT Press, Cambridge, MA, pp. 257-286.

Sekhri, N. and Savedoff, W. (2005), "Private health insurance: implications for developing countries", Bulletin of the World Health Organization, Vol. 83, pp. 127-134.

Smith, B.D. (2012), "Excellence in market access strategy: a research-based definition and diagnostic tool", fournal of Medical Marketing: Device, Diagnostic and Pharmaceutical Marketing, Vol. 12 No. 4, pp. 259-266.

Somé, J., Pasali, S. and Kaboine, M. (2019), "Exploring the impact of healthcare on economic growth in Africa", Applied Economics and Finance, Vol. 6 No. 3, pp. 45-57.

Spena, T.R. and Cristina, M. (2019), "Practising innovation in the healthcare ecosystem: the agency of third-party actors", Fournal of Business E Industrial Marketing, Vol. 35 No. 3, pp. 390-403.

Stark, O. (1999), Altruism and beyond: An Economic Analysis of Transfers and Exchanges within Families and Groups, Cambridge University Press, Cambridge.

Stock, J.H. and Watson, M.W. (2002), "Forecasting using principal components from a large number of predictors", Fournal of the American Statistical Association, Vol. 97 No. 460, pp. 1167-1179.

Thakur, R., Hsu, S.H. and Fontenot, G. (2012), "Innovation in healthcare: issues and future trends", fournal of Business Research, Vol. 65 No. 4, pp. 562-569.

Toumi, M. (2017), Introduction to Market Access for Pharmaceuticals, CRC Press, New York, USA.

Wang, F. (2015), "More health expenditure, better economic performance? Empirical evidence from OECD countries", INQUIRY: The fournal of Health Care Organization, Provision, and Financing, Vol. 52.
Wang, Y., Kung, L. and Byrd, T.A. (2018b), "Big data analytics: understanding its capabilities and potential benefits for healthcare organizations", Technological Forecasting and Social Change, Vol. 126, pp. 3-13.

Wang, K.M., Lee, Y.M., Lin, C.L. and Tsai, Y.C. (2018a), "The effects of health shocks on life insurance consumption, economic growth, and health expenditure: a dynamic time and space analysis", Sustainable Cities and Society, Vol. 37, pp. 34-56.

Weil, D.N. (2014), "Health and economic growth", Handbook of Economic Growth, Vol. 2, Elsevier, pp. 623-682.

Well, D.N. (2007), "Accounting for the effect of health on economic growth", The Quarterly fournal of Economics, Vol. 122 No. 3, pp. 1265-1306.

Wright, G.H. and Taylor, A. (2005), "Strategic partnerships and relationship marketing in healthcare", Public Management Review, Vol. 7 No. 2, pp. 203-224.

Wright, S., Barlow, J. and Roehrich, J.K. (2019), "Publicprivate partnerships for health services: construction, protection and rehabilitation of critical healthcare infrastructure in Europe", Public Private Partnerships, Springer, Cham, pp. 125-151.

Yildirim, D.C. and Calıskan, H. (2020), "The influence of health on economic growth from the perspective of sustainable development: a case of OECD countries", World Fournal of Entrepreneurship, Management and Sustainable Development, Vol. 16 No. 3, pp. 181-194.

\section{Further reading}

Elton, J. and O'Riordan, A. (2016), Healthcare Disrupted: Next Generation Business Models and Strategies, John Wiley and Sons, Hoboken, NJ.

Holmes, S.C. and Miller, R.H. (2003), "The strategic role of ecommerce in the supply chain of the healthcare industry", International fournal of Services Technology and Management, Vol. 4 Nos 4/5/6, pp. 507-517.

Makkonen, H.S. and Johnston, W.J. (2014), "Innovation adoption and diffusion in business-to-business marketing", The fournal of Business and Industrial Marketing, Vol. 29 No. 4, pp. 324-331.

O'Connor, Y. and O'Reilly, P. (2018), "Examining the infusion of mobile technology by healthcare practitioners in a hospital setting”, Information Systems Frontiers, Vol. 20 No. 6, pp. 1297-1317.

\section{Corresponding author}

Antonella Francesca Cicchiello can be contacted at: antonella.cicchiello@unicatt.it 